\title{
Praktik Peracikan Puyer untuk Anak Penderita Tuberkulosis di Indonesia
}

\section{The Practice of Compounded Medicines for Children Suffering from Tuberculosis in Indonesia}

\author{
Selma Siahaan* Ully Adhie Mulyani**
}

\begin{abstract}
*Pusat Humaniora Kebijakan Kesehatan dan Pemberdayaan Masyarakat Badan Penelitian dan Pengembangan Kesehatan, **Pusat Biomedis dan Teknologi Dasar Kesehatan Badan Penelitian dan Pengembangan Kesehatan
\end{abstract}

\begin{abstract}
Abstrak
Masih banyak ditemukan resep obat antituberkulosis anak dengan kombinasi beberapa obat dalam racikan puyer yang tidak sesuai standar program pemberantasan tuberkulosis (TB) paru Kementerian Kesehatan Republik Indonesia. Studi ini bertujuan untuk mengetahui situasi dan permasalahan berhubungan praktik peresepan puyer sebagai obat anti tuberkulosis (OAT). Pada periode Mei hingga Desember tahun 2009, penelitian diawali dengan pengukuran persentase peracikan OAT dalam bentuk puyer, dilanjutkan dengan penelitian kualitatif eksploratif. Data dikumpulkan dari rumah sakit, puskesmas, apotek dan dinas kesehatan di Jakarta, Bandung, Medan, dan Makassar. Pada tiap fasilitas kesehatan, 30 sampel resep pengobatan diambil untuk pasien tuberkulosis anak usia 1 - 12 tahun. Kemudian dilakukan wawancara mendalam terhadap dokter anak, apoteker, keluarga pasien, dan pegawai dinas kesehatan yang terkait. Penelitian menemukan persentase peracikan OAT adalah 25\% untuk campuran rifampicin dan isoniazid, dan $18 \%$ untuk campuran rifampicin, isoniazid, dan pyrazinamid. Semua informan menyadari bahwa praktik peracikan puyer tergolong pengobatan yang irasional, tetapi situasi yang mereka hadapi membuat mereka terus meresepkan dan membuat peracikan puyer. Ketersediaan fixed dose combination (FDC) yang rendah untuk OAT serta harga yang mahal menjadi alasan utama. Pemerintah dan organisasi profesi perlu meningkatkan pembinaan secara terus menerus kepada tenaga kesehatan berhubungan serta meningkatkan akses masyarakat terhadap FDC untuk tuberkulosis anak.
\end{abstract}

Kata kunci: Fixed dose combination, obat antituberkulosis anak, puyer

\section{Abstract}

There are still many practices of treating sick children with a mixture of several medicines for children suffering from tuberculosis, called it "puyer". It is not following the standard from Ministry of Health. This study explored the complex situation dealing with the practice of compounded medicines. It was innitially by assessment the percentage of "puyer" prescription, and followed by the qualitative study, from May to December 2009. Data were collected from hospitals, primary health cares and pharmacies in Jakarta, Bandung, Medan, and Makassar. From every health cares facilities, 30 prescriptions were collected for children age 1 to 12 years old. Then, we conducted in-depth interviews with pediatricians, pharmacist, patients' families and health officers about "puyer" prescription for children. The prevalence of prescription consists of "puyer" for children were $25 \%$ for isoniazid and rifampicin and $18 \%$ for isoniazid, pyrazinamid, and rifampicin. All informants knew "puyer" prescription is irrational, because the complex situation they faced they continued to give "puyer" to patients. Low availability and high price of fixed doses combination (FDC) are main reasons. The government and association of doctors/pharmacist should enforce discipline to their member to obey therapy standard. The government should improve access to FDC medicines for children suffering tuberculosis.

Keywords: Fixed doses combination, tuberculosis medicines, compounded medicines

\section{Pendahuluan}

Prevalensi anak yang menderita tuberkulosis di Indonesia meliputi anak di bawah usia 1 tahun $(0,47 \%)$, anak usia $1-<5$ tahun $(0,53 \%)$, dan anak $5-14$ tahun $(0,53 \%) .{ }^{1}$ Menurut World Health Organitation (WHO), setiap tahun, lebih dari 100.000 anak meninggal karena tuberkulosis (TB). ${ }^{2}$ Kondisi sosial ekonomi yang kurang, kepadatan penduduk dan gizi buruk meningkatkan risiko tertular penyakit TB. ${ }^{3}$ Untuk mengatasi hal tersebut, perlu ditingkatkan akses terhadap obat tuberkulosis yang efektif. Oleh sebab itu, Indonesia memerlukan strategi

Alamat korespondensi: Selma Siahaan, Pusat Humaniora Kebijakan Kesehatan dan Pemberdayaan Masyarakat Balitbangkes, Jl. Percetakan Negara 23A Jakarta Pusat 10560,Hp.081382754097,e-mail: selmasiahaan@yahoo.com 
intervensi kesehatan masyarakat yang cocok, agar resisten terhadap obat TB dapat diminimalisasi.

Kementerian Kesehatan Republik Indonesia telah mengeluarkan pedoman standar penatalaksanaan pengobatan TB paru pada anak. ${ }^{4}$ Program distribusi obat paru juga telah dijalankan, berupa obat antituberkulosis (OAT) kombipak anak atau fixed combination dosed (FDC) yang tersedia dalam bentuk tablet dan kapsul. Untuk anak dengan berat badan $10-20 \mathrm{~kg}$, dilakukan pengobatan dalam dua tahap meliputi fase intensif (fase I) selama 2 bulan dengan memberikan isoniazid (H=I$\mathrm{NH}$ ) tablet $100 \mathrm{mg}$, rifampicin (R) $75 \mathrm{mg} 2 \mathrm{kapsul}$, dan pyrazinamid $200 \mathrm{mg} 2$ tablet, dilanjutkan fase 2 selama 4 bulan dengan isoniazid $100 \mathrm{mg} 100 \mathrm{mg}$ dan rifampicin $75 \mathrm{mg} 2$ kapsul. ${ }^{4-6}$

Namun, dalam praktik di lapangan, masih ditemukan terapi yang tidak baku dan peracikan puyer OAT yang tidak sesuai dengan pedoman tersebut dengan dua, tiga atau empat obat seperti isoniazid, rifampicin, pyrazinamid. Bahkan, ethambutol yang seharusnya diracik dari tablet sediaan OAT dewasa, dengan dosis disesuaikan untuk anak. Juga ditemukan beragam resep yang kadangkadang tidak sesuai dengan ketentuan dari program pemberantasan TB paru. ${ }^{4}$

Campuran OAT anak diracik lege artis di apotek. Peracikan dilakukan dengan menggunakan tablet atau kapsul untuk orang dewasa atau tablet/kapsul untuk anak sesuai dengan usia atau berat badan anak. Sejumlah obat yang diinginkan, digerus secara bersama-sama atau terpisah menjadi bentuk bubuk, dibungkus dengan kertas perkamen dan diserahkan untuk penggunaan satu bulan. Penebusan diulang (iterasi) beberapa kali untuk penggunaan selama enam bulan. ${ }^{4}$ Menebus obat tidak selalu dilakukan di satu apotek, kadang-kadang dilakukan di beberapa apotek sehingga memungkinkan terjadi perbedaan kadar hasil racikan puyer. Masing-masing zat aktif ini mempunyai sifat fisika yang berbeda, rifampicin sangat higroskopis dan sensitif terhadap sinar matahari. Oleh karena itu, rifampisin tidak boleh dicampur dalam satu racikan puyer dengan OAT yang lain., 5, Cara peracikan di apotek tidak sama dengan pembuatan obat di pabrik yang memenuhi syarat cara pembuatan obat yang baik (CPOB).

Di samping itu, penyimpanan pada suhu tertentu dan kelembapan udara dapat me-mengaruhi kualitas dan stabilitas OAT anak hasil racikan berdasarkan resep dokter. Konsentrasi rifampicin, isoniazid, dan pyrazinamid yang diracik dan disimpan selama 30 hari mengalami penurunan. ${ }^{8}$ Jika kombinasi rifampicin dan isoniazid tidak stabil, secara biologis dapat terjadi degradasi rifampicin dalam asam lambung yang dikatalis oleh isoniazid (INH) sehingga menyebabkan penurunan $35 \%$ bioavailabilitas rifampicin. WHO dan International Union Against Tuberculosis and Lung Disease's (IUATLD) men- syaratkan bioavailabilitas kombinasi ketiga obat ini harus diawasi dengan baik. Paling tidak, harus dilakukan pengawasan terhadap bioavalabilitas rifampisin dalam kombinasi tersebut. ${ }^{7}$

Dampak praktik peracikan yang tidak sesuai dengan pedoman tersebut meningkatkan resistensi kuman Mycobacterium tuberculosis terhadap OAT sehingga permasalahan TB pada anak tersebut tidak akan tuntas. ${ }^{9}$ Artikel ini bertujuan mengetahui situasi dan permasalahan yang berhubungan praktik peresepan OAT anak dalam bentuk racikan puyer dari perspektif dokter, apoteker, pemegang program berhubungan dan pasien.

\section{Metode}

Penelitian ini diawali dengan pengukuran persentase peresepan puyer untuk obat antituberkulosis anak secara potong lintang untuk memperoleh gambaran besar persentase puyer anak yang ada di fasilitas kesehatan. Selanjutnya, dilakukan studi kualitatif eksploratif untuk menggali dan memahami situasi dan permasalahan lapangan berhubungan praktik peresepan puyer OAT anak. Lokasi pengambilan data adalah di dinas kesehatan kota, rumah sakit, puskesmas, dan apotek pada kota besar yang terdapat puskesmas dan rumah sakit yang mempunyai program penanggulangan paru secara intensif di pulau Jawa dan luar Jawa, meliputi Jakarta, Bandung, Medan, dan Makassar. Fasilitas kesehatan dipilih secara purposif, yaitu yang banyak mempunyai pasien paru dan mempunyai program penanggulangan paru secara intensif. Di setiap kota tersebut dipilih 1 rumah sakit pemerintah, 2 puskesmas serta 3 apotek komunitas. Untuk memperoleh gambaran persentase peresepan puyer untuk obat antituberkulosis, dilakukan survei cepat dengan perhitungan jumlah sampel mengikuti survei cepat yang dikembangkan oleh WHO, yaitu 30 sampel. Oleh karena itu, diambil 30 sampel resep pengobatan untuk pasien anak usia 1 tahun sampai dengan 12 tahun dengan diagnosis tuberkulosis, pada hari pengumpulan data dan apabila tidak cukup diambil resep pada hari berikutnya.

Pada fasilitas kesehatan yang sama, dilakukan wawancara mendalam pada dokter anak, apoteker, dan keluarga pasien tentang situasi dan permasalahan seputar resep racikan puyer. Selain itu, Peneliti juga melakukan wawancara kepada pejabat dinas kesehatan yang berhubungan dengan permasalahan obat tuberkulosis anak untuk menggali sejauh mana dinas kesehatan memahami permasalahan resep racikan puyer dan apa saja program berhubungan. Data kuantitatif dianalisis secara statistik deskriptif. Data kualitatif dianalisis secara triangulasi dengan berbagai sumber data dan didiskusikan dalam tim dan dengan pakar yang kemudian dituangkan ke dalam matriks secara tematik. Lama penelitian ini 8 
bulan, sejak bulan Mei sampai dengan Desember 2009. Informan di setiap kota terdiri dari 7 dokter, 12 apoteker, 10 keluarga pasien, dan 4 dinas kesehatan.

\section{Hasil}

Jumlah resep yang dapat dianalisis adalah 422 lembar resep yang berasal dari rumah sakit, puskesmas, dan apotek di empat kota besar meliputi Jakarta, Bandung, Medan, dan Makasar. Sekitar 36,5\% ( $=154)$ lembar resep diperoleh dari rumah sakit. Resep yang diperoleh dari puskesmas adalah 9,5\% $(n=40)$ lembar, sedangkan dari apotek 54\% ( $n=228)$ lembar. Obat yang dapat terbaca dengan jelas pada resep dianalisis, jumlah item obat OAT yang dianalisis adalah 599 item obat. Penelitian ini menemukan sekitar 57\% ( $\mathrm{n}=341)$ adalah sediaan tunggal OAT, sedangkan sisanya adalah dalam bentuk puyer yang terdiri dari $25 \%(\mathrm{n}=150)$ campuran puyer rifampicin dan isoniazid, dan $18 \%(\mathrm{n}=108)$ campuran rifampicin, isoniazid, dan pyrazinamid. Kisaran durasi penggunaan obat adalah 3 hari hingga 100 hari. Sebagian besar obat diresepkan untuk digunakan selama 30 hari $(53 \%)$.

Tabel 1. Pendapat Informan Secara Umum Tentang Peresepan Puyer untuk Anak

\begin{tabular}{|c|c|}
\hline Informan & Pendapat \\
\hline Dokter & $\begin{array}{l}\text { Peresepan puyer untuk anak dapat disesuaikan dengan kondisi dan kebutuhan anak, dalam hal dosis, harus sesuai } \\
\text { dengan berat badan anak. } \\
\text { Peresepan puyer untuk anak dapat mengurangi efek terapi obat, tetapi dibutuhkan untuk efisiensi dan memudahkan } \\
\text { pemberian obat kepada anak. } \\
\text { Peresepan puyer merupakan solusi untuk obat-obat yang bentuk sediaannya tidak cocok untuk anak. } \\
\text { Peresepan puyer lebih murah untuk pasien. }\end{array}$ \\
\hline Apoteker & $\begin{array}{l}\text { Peresepan puyer telah merupakan tradisi di Indonesia walaupun peresepan puyer merupakan pengobatan yang tidak } \\
\text { rasional. } \\
\text { Pemberian puyer bertujuan untuk memudahkan minum obat secara oral. } \\
\text { Peresepan puyer bertujuan untuk memudahkan penyesuaian dosis pada anak karena bisa disesuaikan dengan umur } \\
\text { dan berat badan anak. } \\
\text { Peresepan puyer tidak stabil karena sifat obat yang higroskopis dan aspek higienitasnya tidak dapat } \\
\text { dipertanggungjawabkan. } \\
\text { Peresepan puyer memudahkan pemberian kombinasi obat (polifarmasi) pada anak. } \\
\text { Peresepan puyer lebih ekonomis (harga lebih murah). }\end{array}$ \\
\hline Keluarga pasien & Puyer mudah untuk diberikan kepada anak. \\
\hline Dinas kesehatan & $\begin{array}{l}\text { Peresepan puyer merupakan peresepan yang tidak rasional karena dapat mengurangi dosis dan dapat menimbulkan } \\
\text { efek samping lainnya. Khususnya jika telah tersedia obat-obat untuk anak dalam bentuk sediaan. Dalam sediaan } \\
\text { tersebut, telah tercantum cara pakai dan takaran dosis sesuai dengan usia anak. } \\
\text { Puyer masih rasional, asalkan pada saat pengerjaan masih memperhatikan higienitas, ruang racik harus higienis } \\
\text { untuk menghindari kontaminasi silang. Ruang racik harus tertutup, terpisah dari ruang lain/khusus. }\end{array}$ \\
\hline
\end{tabular}

Tabel 2. Pendapat Tentang Keuntungan Peresepan Puyer Menurut Informan

\begin{tabular}{ll}
\hline Informan & \multicolumn{1}{c}{ Pendapat } \\
\hline Dokter & Memudahkan dalam pemberian obat kepada anak. \\
& Dosis dapat disesuaikan dengan berat badan anak. \\
& Lebih praktis dalam hal pemberian, terutama untuk obat yang dikombinasikan. \\
& Lebih ekonomis (tidak mahal). \\
Apoteker & Lebih mudah mengatur dosis, karena dapat disesuaikan dengan berat badan anak secara lebih tepat. \\
& Lebih ekonomis (lebih murah). \\
& Lebih mudah diberikan kepada anak karena hanya memberikan satu macam yang terdiri dari berbagai gabungan obat. \\
& Cara pemberian lebih mudah untuk anak yang tidak dapat menelan bentuk sediaan tablet. \\
& Menguntungkan bagi petugas apotek karena ada tambahan biaya racikan. \\
& Mudah diberikan dan mudah untuk ditelan anak. \\
Keluarga pasien & Mudah untuk disimpan. \\
& Dapat diminum bersama vitamin (ditambah vitamin). \\
& Obat dapat ditebus setengah dari jumlah obat yang diresepkan, sedangkan bentuk sediaan sirup tidak bisa ditebus \\
setengahnya. & \\
& Obat racikan efektif karena pemakaiannya mudah dan sederhana. \\
& Obat racikan termasuk stabil apabila sifat obatnya sendiri stabil.
\end{tabular}


Ringkasan wawancara mendalam tentang praktik peresepan puyer anak, tidak terbatas hanya untuk puyer OAT dari pandangan dokter, apoteker, keluarga pasien, dan dinas kesehatan (Tabel 1).

\section{Keuntungan dan Kerugian Peresepan Puyer}

Informan juga ditanyakan tentang aspek keuntungan peresepan puyer yang mendorong informan untuk tetap memberikan puyer kepada pasien anak (Tabel 2). Selain itu, informan juga ditanyakan tentang kelemahan peresepan puyer (Tabel 3).
Peresepan Puyer untuk Pasien Anak Penderita Tuberkulosis Secara khusus, informan juga menyampaikan pendapatnya tentang puyer anak untuk pasien TB (Tabel 4). Pejabat dinas kesehatan menyatakan bahwa Kementerian Kesehatan telah mengeluarkan panduan tentang peresepan obat yang rasional yaitu "Modul Pelatihan Penggunaan Obat Rasional”, tetapi untuk peracikan puyer belum ada sehingga perlu dibuatkan peraturannya untuk mengantisipasi peracikan yang tidak rasional dan mengikat apoteker untuk mengikuti aturan tersebut. Sejauh ini penyediaan obat antituberkulosis kombipak diadakan

Tabel 3. Pendapat Tentang Kerugian Peresepan Puyer Menurut Informan

\begin{tabular}{|c|c|}
\hline Informan & Pendapat \\
\hline Dokter & $\begin{array}{l}\text { Dalam proses peracikan perlu waktu lebih lama. } \\
\text { Dapat terjadi interaksi obat. } \\
\text { Kemungkinan timbul masalah higienitas. } \\
\text { Dapat terjadi penurunan bioavailabilitas obat. } \\
\text { Selama penyimpanan dapat terjadi penurunan konsentrasi obat. } \\
\text { Rasanya pahit. }\end{array}$ \\
\hline Apoteker & $\begin{array}{l}\text { Lebih memungkinkan untuk terjadi efek samping. } \\
\text { Memungkinkan terjadi interaksi obat. } \\
\text { Kontrol kualitas obat sulit dilakukan karena tingginya kemungkinan tingkat kesalahan manusia (dokter/petugas } \\
\text { apotek). } \\
\text { Mungkin terjadi ketidakseragaman bobot karena dalam pembagian pulveres/serbuk tidak ditimbang satu per satu. } \\
\text { Mungkin terjadi ketidaktepatan dosis dalam pembuatan. } \\
\text { Mungkin terjadi penurunan stabilitas obat. } \\
\text { Rasanya pahit. } \\
\text { Merepotkan karena perlu waktu dalam peracikan. } \\
\text { Lebih sulit diberikan pada anak. }\end{array}$ \\
\hline Keluarga pasien & $\begin{array}{l}\text { Pada waktu menyiapkan bisa terjadi ada serbuk yang tumpah atau terbuang. } \\
\text { Rasa obat pahit. }\end{array}$ \\
\hline Dinas kesehatan & $\begin{array}{l}\text { Efektivitas dan stabilitas obat racikan dapat berkurang apalagi apabila di dalam campuran tersebut terdapat obat-obat } \\
\text { yang tidak dapat tercampur kemudian dalam sediaan puyer kemungkinan dapat terjadi interaksi antara komponen } \\
\text { obat. } \\
\text { Obat dapat diracik hanya untuk tiga hari. Untuk OAT diberikan sebulan karena pendidikan kurang rumahnya lembap } \\
\text { sehingga susah untuk memantau stabilitas puyer OAT yang diresepkan tiga puluh hari. }\end{array}$ \\
\hline
\end{tabular}

Tabel 4. Pendapat Tentang Peresepan Puyer untuk Tuberkulosis Anak Menurut Informan

\begin{tabular}{|c|c|}
\hline Informan & Pendapat \\
\hline Dokter & $\begin{array}{l}\text { Peresepan puyer TB diberikan sesuai kebutuhan pasien dengan mempertimbangkan aspek kesehatan dan kenyamanan. } \\
\text { Puyer TB diberikan kepada pasien yang tidak mampu membeli obat sirup atau FDC, dan banyak penderita TB yang } \\
\text { merupakan pasien tidak mampu. } \\
\text { Peresepan puyer TB untuk mengatasi ketidaktersediaan obat yang dibutuhkan, misalnya kombipak (FDC) anak tidak } \\
\text { selalu tersedia. } \\
\text { Peresepan puyer TB dari obat generik lebih murah dibandingkan dengan obat paten. }\end{array}$ \\
\hline Apoteker & $\begin{array}{l}\text { Peresepan puyer TB untuk anak hanya sebagai alternatif yang murah untuk menekan biaya pengobatan. } \\
\text { Puyer TB diresepkan karena tidak tersedianya bentuk sediaan dan dosis obat TB yang sesuai bagi anak. }\end{array}$ \\
\hline Dinas kesehatan & $\begin{array}{l}\text { Peresepan puyer OAT merupakan peresepan yang tidak rasional karena dapat memengaruhi aktivitas dan efektivitas } \\
\text { dari komponen obat yang terdapat dalam sediaan puyer. } \\
\text { OAT yang dipuyerkan tidak rasional karena dosis tidak sama pencampurannya, ada yang kurang ada yang lebih, jum- } \\
\text { lah obat TB rata-rata (dibuat) dalam jumlah besar. } \\
\text { Penyimpanan kurang aman. } \\
\text { Puyer OAT tidak rasional karena telah ada kombipak (FDC). Namun sulit untuk diberikan pada bayi. Untuk anak yang } \\
\text { tidak bisa menelan dapat dipuyerkan, namun harus tepat dosis. }\end{array}$ \\
\hline
\end{tabular}


berdasarkan kebutuhan puskesmas. Proses pengadaan obat tersebut di pusat yang kemudian diantarkan ke dinas kesehatan provinsi untuk disalurkan ke dinas kesehatan kabupaten/kota dan selanjutnya didistribusikan ke puskesmas. Dinas kesehatan tidak mendistribusikan kombipak ke rumah sakit dan apotek pemerintah. Sejauh ini kombipak yang diterima oleh dinas kesehatan adalah kombipak untuk obat anti tuberkulosis dewasa dan belum pernah menerima kombipak untuk antituberkulosis anak. Petugas dinas kesehatan berpendapat bahwa sebaiknya disediakan kombipak untuk obat anti tuberkulosis anak dalam bentuk sirup dengan kemasan yang tidak mudah rusak.

\section{Pembahasan}

Presentasi peracikan OAT meliputi 25\% untuk campuran rifampicin dan isoniazid, dan $18 \%$ untuk campuran rifampicin, isoniazid, dan pyrazinamid. Pada dasarnya, pengobatan tersebut telah cukup umum dan sesuai dengan standar apabila diberikan dalam satu paket pengobatan yang disiapkan oleh pabrik dalam bentuk tablet ataupun sirup yang dosisnya dapat disesuaikan dengan kebutuhan anak. 4,9,10 Akan tetapi, berbeda jika ketiga obat tersebut dicampur secara manual dan dijadikan puyer. Praktik yang manual dan tidak terstandar dapat menyebabkan penggunaan obat yang irasional karena selama proses pencampuran dan penyimpanan obat tersebut dapat terjadi penurunan stabilitas obat-obat tersebut yang berdampak terhadap penurunan potensi/ kadar dari obat. Jika potensinya telah berkurang, dapat timbul resistensi obat sehingga pasien menjadi tidak sembuh. Hal ini juga dapat menyebabkan eradikasi kuman Mycobacterium tuberculosis tidak tuntas dan memperparah kejadian multidrug resistance tuberculosis (MDR TB). $6,11,12$

Wawancara mendalam dilakukan terhadap profesional yang berhubungan peracikan puyer tersebut, pemangku program, dan pengguna puyer. Dari hasil wawancara, dapat dikatakan bahwa dokter, apoteker, dan petugas dinas kesehatan pada umumnya telah menyadari bahwa praktik peracikan puyer itu kurang dapat dibenarkan dan tergolong pengobatan yang irasional. Akan tetapi, dengan situasi yang mereka hadapi, mereka harus membuat keputusan praktis untuk terapi pasien anak yang menderita tuberkulosis sehingga praktik peracikan puyer terus berjalan. Ketersediaan yang rendah dari FDC untuk OAT serta harga yang mahal menjadi alasan utama. ${ }^{13}$

Berdasarkan Pedoman Nasional Tuberkulosis Anak yang dibuat oleh Ikatan Dokter Anak Indonesia (IDAI), peracikan rifampicin yang dicampur jadi satu dengan OAT lain tidak diperbolehkan. ${ }^{14}$ Bukan hanya dokter yang sepenuhnya bertanggung jawab terhadap peresepan irasional kepada pasien, tetapi apoteker juga harus menjalankan konsep standar asuhan kefarmasian untuk mengatasi permasalahan terapi obat, meningkatkan rasionalitas pengobatan sehingga luaran terapi yang baik dan kualitas hidup pasien dapat ditingkatkan. ${ }^{15}$ Pada kenyataannya apoteker yang bertugas di apotek sering tidak menyampaikan informasi pengobatan yang baik kepada pasien. ${ }^{16}$ Hal ini juga tergambar dari hasil wawancara dengan keluarga pasien. Tidak satupun informan yang mengatakan bahwa obat puyer merupakan pengobatan yang kurang baik. Dengan kata lain pasien belum mendengar bahwa puyer itu pengobatan yang belum benar.

Hal yang menarik adalah bahwa pemegang program dari dinas kesehatan mengakui belum ada pedoman atau kebijakan yang berkaitan dengan praktik peracikan puyer. Demikian juga program penyediaan FDC untuk OAT anak, hanya terbatas pada puskesmas belum menjangkau rumah sakit. Program tersebut juga belum merata di seluruh Indonesia dan masih berjalan tersendat. OAT program untuk bayi juga belum tersedia. Kementerian Kesehatan juga belum mengeluarkan kebijakan berhubungan praktik peresepan puyer, walaupun laporan WHO menyatakan bahwa praktik tersebut merupakan pengobatan irasional dan sebaiknya tidak digunakan serta berisiko menimbulkan efek samping. ${ }^{17}$

Pedoman yang ada baru terbatas Pedoman Nasional Tuberkulosis Anak yang dikeluarkan Ikatan Dokter Anak Indonesia yang menyatakan bahwa peracikan rifampicin yang dicampur dengan OAT lain tidak diperbolehkan karena sifat kimia rifampicin yang higroskopis dan sensitif terhadap sinar matahari dapat menyebabkan rusaknya rifampicin sehingga mengganggu potensi obat. ${ }^{18}$ Hasil penelitian ini menunjukkan bahwa pedoman tersebut cukup sering tidak dijalankan oleh dokter.

Apabila dibandingkan dengan negara maju, praktik peracikan beberapa obat yang dicampur secara manual menjadi satu juga masih berjalan. Akan tetapi, terbatas untuk obat-obat yang tidak tersedia di pasaran dan/atau memenuhi persyaratan yang ketat, misalnya seseorang yang benar-benar tidak dapat menelan dapat dibuatkan racikan sirup. ${ }^{19}$ Pada waktu pelayanan obat, apoteker harus dengan jelas memberikan informasi tentang keuntungan dan kerugian puyer kepada pasien. Pada umumnya, praktik peracikan yang masih agak umum adalah untuk pencampuran obat-obat steril di rumah sakit yang telah mempunyai fasilitas yang sesuai dan standar serta untuk pembuatan salep. Sedangkan, praktik beberapa macam tablet obat digerus menjadi satu lebih banyak digunakan untuk pengobatan hewan. Oleh karena itu, sebaiknya praktik peracikan OAT dan obat lain yang tidak rasional pelan-pelan harus mulai ditinggalkan. Untuk itu, diperlukan pembinaan yang terus menerus dari pemerintah dan organisasi profesi. 


\section{Kesimpulan}

Permasalahan praktik peresepan puyer disebabkan oleh program penyediaan FDC untuk OAT anak yang baru terbatas pada puskesmas, hanya sedikit, bahkan belum menjangkau rumah sakit, ketersediaan yang rendah dari kombipak OAT anak pada rumah sakit dan apotek, serta harga kombipak OAT anak yang sangat mahal. Situasi dan permasalahan tersebut dijadikan dasar bagi petugas kesehatan untuk terus meresepkan dan membuat peracikan puyer, walaupun mereka menyadari bahwa praktik peracikan puyer tergolong pengobatan yang irasional. Selain itu, belum ada kebijakan teknis tentang praktik peresepan puyer.

\section{Saran}

Kementerian Kesehatan dan dinas kesehatan perlu menjaga kelangsungan program penyediaan fixed dose combination (FDC) untuk obat antituberkulosis (OAT) anak, agar keterjangkauan masyarakat terhadap OAT tersebut meningkat. Organisasi IDAI dan Ikatan Apoteker Indonesia (IAI) harus mengupayakan pendisiplinan bagi anggotanya untuk memberikan terapi dan pelayanan obat yang sesuai dengan standar guna kesembuhan pasien. Dinas kesehatan perlu menjalankan upaya promosi kesehatan bagi masyarakat dan pembinaan bagi penyedia jasa kesehatan berhubungan praktik peracikan puyer. Kementerian Kesehatan mengeluarkan kebijakan berhubungan praktik peracikan puyer agar tidak menimbulkan kebingungan dan keresahan bagi tenaga kesehatan dan masyarakat.

\section{Ucapan Terima kasih}

Terima kasih kepada teman-teman, Ibu Anni V Purba dan Ida Diana Sari yang membantu penelitian, serta terakhir kepada Dessy Gusmali yang turut menyumbangkan pikiran bagi proposal penelitian ini.

\section{Daftar Pustaka}

1. Departemen Kesehatan Republik Indonesia. Laporan hasil riset kesehatan dasar (Riskesdas) Indonesia tahun 2007. Jakarta: Badan Penelitian dan Pengembangan Kesehatan Departemen Kesehatan Republik Indonesia; 2008.

2. World Health Organization. Global tuberculosis control-epidemiology, strategy, financing. WHO report 2009 [cited 2009 Aug 31]. Available from: http://www.who.int/tb/publications/global_report/2009/en/index.html.

3. Djaja Sarimawar, Sudani O, Lolong DB. Determinan upaya pengobatan tuberkulosis pada anak di bawah umur 15 tahun. Jurnal Ekologi Kesehatan. 2009; 8(3): 1004-14.

4. Departemen Kesehatan Republik Indonesia. Buku pedoman nasional penanggulangan tuberkulosis. Jakarta: Departemen Kesehatan Republik
Indonesia; 2000.

5. Departemen Kesehatan Republik Indonesia. Farmakope Indonesia edisi IV. Jakarta: Direktorat Jenderal Pengawasan Obat dan Makanan Republik Indonesia; 1995.

6. Prapti IY. Studi kohor tata laksana diagnosa dan pengobatan primer komplek tuberkulosis. Jakarta: Badan Penelitian dan Pengembangan Kesehatan; 2003.

7. Fourie PB, Spinaci S. Structures required, roles and responsibilities in maintaining laboratories for quality assurance of antituberkulosis fixed combinations in accordance with the IUATLD/WHO statement. International Journal of Tuberculosis and Lung Disease. 1999 Nov; 3 (11 Suppl3): S368-70.

9. Gusmali D, Diana Sari I, Raini M. Laporan Penelitian: Survai Resep dan Racikan Obat TB Paru di Beberapa Apotek di Jakarta. Jakarta: Badan Litbang Kesehatan; 2004.

10. Utami Eka Rahayu. Antibiotika, resistensi, dan rasionalitas terapi. Sainstis. 2012; 1(1): 124-38

11. Chuluq A C, Abijoso, Sidharta B. Pengembangan paket obat SOT (sediaan obat tunggal) untuk pengobatan tuberkulosa. Buletin Penelitian Kesehatan. 2004; 32 (3): 127-34.

12. World Health Organization. Promoting safety of medicines for children. France: World Health Organization; 2007.

13. Singh S, Mohan B. A pilot stability study on four-drug-fixed-dose combination anti-tuberculosis products. International Journal of Tuberculosis and Lung Disease. 2003; 7(3): 298-303.

14. Siahaan S. Laporan penelitian: studi harga obat di rumah sakit, puskesmas dan apotek. Jakarta: Badan Penelitian dan Pengembangan Kesehatan; 2012.

15. Rahajoe N, Basir D, Makmuri MS, Kartasasmita CB, ed. Pedoman nasional tuberkulosis anak. Edisi ke-2. Jakarta: UKK Respirologi PP IDAI; 2007.

16. Holloway K, editor. Drug and the therapeutics comittee, a practical guide. Geneva: World Health Organization; 2003.

17. Herman MJ, Handayani RS, Siahaan S. Kajian praktik kefarmasian apoteker pada tatanan rumah sakit. Kesmas Jurnal Kesehatan Masyarakat Nasional. 2012; 7(8): 365-72.

18. World Health Organization. Technical report: of the 17th expert committee on the selection and use of essential medicines. Geneva: WHO; 2009 [manuscript on internet]. Available from: http://www.who.int/selection_medicines/committees/expert/17/en/.

19. Buurma Henk. Frequency, nature and determinants of pharmacy compounded medicines in Dutch community pharmacies. Pharmacy World \& Science. 2003; 25(6): 280-7.

20. Kairuz T, Chhim S, Hasan F, Kumar K, Lal A, Roshni P, et al. Extemporaneous compounding in a sample of New Zealand hospitals: a retrospective survey. J New Zealand Med Assoc [serial on internet]. 2007 March [cited 2011 Jan 20]; 120(1251). Available from: file:C:/artikel\%20compounding $\% 20$ medicines/Extemporaneous $\% 20 \mathrm{com}$ pounding $\% 20$ in $\% 20 \mathrm{a} \% 20$ sample $\% 20$ of $\% 20$ New $\% 20$ Zealand $\%$ 20hospitals $\% 20 \% 20$ a $\% 20$ retrospective $\% 20$ survey.htm. 